\title{
Aneurysms of the middle meningeal artery
}

\author{
N. O. AMELI \\ From the Department of Neurosurgery, University of Tehran, Iran
}

\begin{abstract}
Aneurysms of the middle meningeal artery have rarely been diagnosed. We were able to find 10 cases in the literature (Schulze, 1957; Pouyanne, Leman, Got, and Gouaze, 1959; Kia-Noury, 1961; Markwalder and Huber, 1961, two cases; Berk, 1961; Dilenge and Ruthrich, 1962; Hirsch, David, and Sachs, 1962; Wortzman, 1963; and Kuhn and Kugler, 1964). In this paper another case is reported. In all these cases except one (Berk, 1961) there was a history of trauma, often not more than a fall, days or weeks before the aneurysm was discovered. In six cases the aneurysms were histologically examined. In these the wall of the aneurysms were formed by fibrous tissue with no trace of arterial structure, and they were therefore considered to be 'false' aneurysms. In the case reported by Berk it was considered to be a congenital aneurysm although no histological examination is mentioned. In the case reported below the aneurysmal wall had the characteristics of a true aneurysm with evidence of rupture and subsequent healing.
\end{abstract}

\section{CASE REPORT}

M.M.K. (23546), a man aged 23, was admitted to the Neurosurgical Service of the Pahlavi Hospital on 18 August 1963. Forty days before admission he sustained a blow on the head during a fist fight. An hour later he complained of severe headache and vomited four times, and rapidly lost consciousness. He was admitted to a local hospital where he regained consciousness after four days, but he was still irritable and incoherent. It was then noticed that his memory for recent events was poor. He would forget his mother's visits a few minutes after she had left his bedside.

He was admitted to the neurosurgical service because of ptosis, slight headache, and behaviour disturbance. $\mathrm{He}$ had become clumsy in all his actions since the accident, careless in eating and appearance, and indifferent to other people's wishes. He thought that he was quite fit and did not need any treatment. There was no previous history of head injury or headache before the injury received 40 days before admission.

On examination he was a pale young man who resented examination. He was right handed and there was no speech disturbance. The optic fundi were normal. There was a left third nerve paralysis with ptosis and a moderately dilated pupil. Apart from slight right facial weakness there were no other abnormalities found in examining the central nervous system. Straight radiographs of the skull were normal. A left common carotid angiogram showed an aneurysm presumably arising from the left middle meningeal artery with some deviation of the middle cerebral artery upwards and inwards (Figs. 2 and 3). Angiography was repeated four days later. In the early arterial phase before the external carotid system was filled the aneurysm could not be seen (Fig. 1), but in the venous phase the aneurysm was again visualized (Fig. 4). From the history and the last angiogram a diagnosis of extradural haematoma, low down in the middle fossa, due to rupture of an aneurysm of the middle meningeal artery, was made.

OPERATION Under general anaesthesia a left temporal osteoplastic flap was turned down. An extradural haematoma separated from bone by a thin translucent layer of fibrous tissue was exposed. A large quantity of dark blood clot was evacuated from the middle fossa under the dura. The haematoma extended well towards the midline, and after its removal the aneurysm was found by palpation of the dural surface with finger tips as it could not be seen. The aneurysm was embedded in the dura with an external flat surface, which was difficult to differentiate from the surrounding dura. The aneurysm and its arterial connexions were carefully dissected off

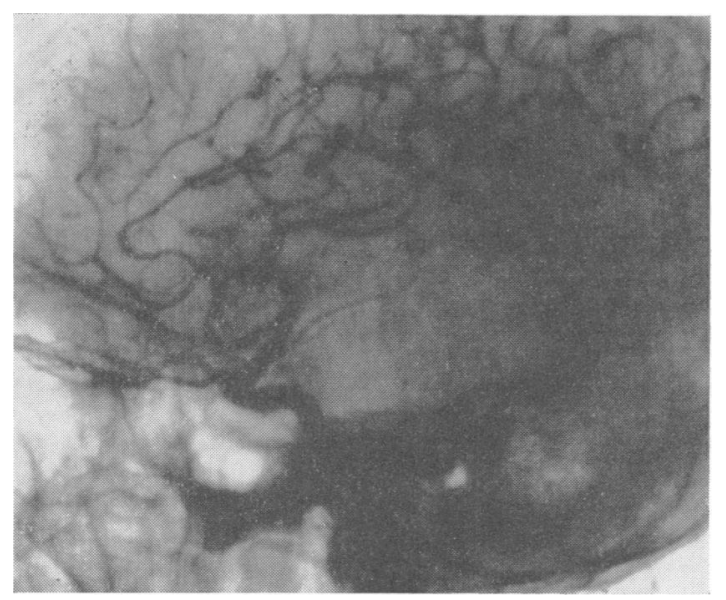

Fig. 1. Early arteriogram (lateral view). No filling of external carotid system. Sylvian vessels and anterior choroidal artery are displaced upwards. 


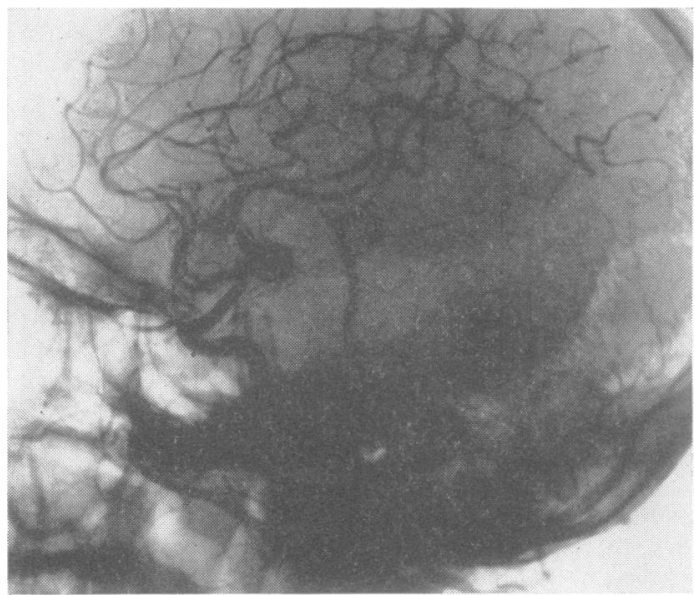

FIG. 2. Later arteriogram with filling of the external carotid system. Aneurysm is well shown. The large middle meningeal artery is seen entering the aneurysm. The tramway appearances of the vessels leaving the aneurysm should be noted.

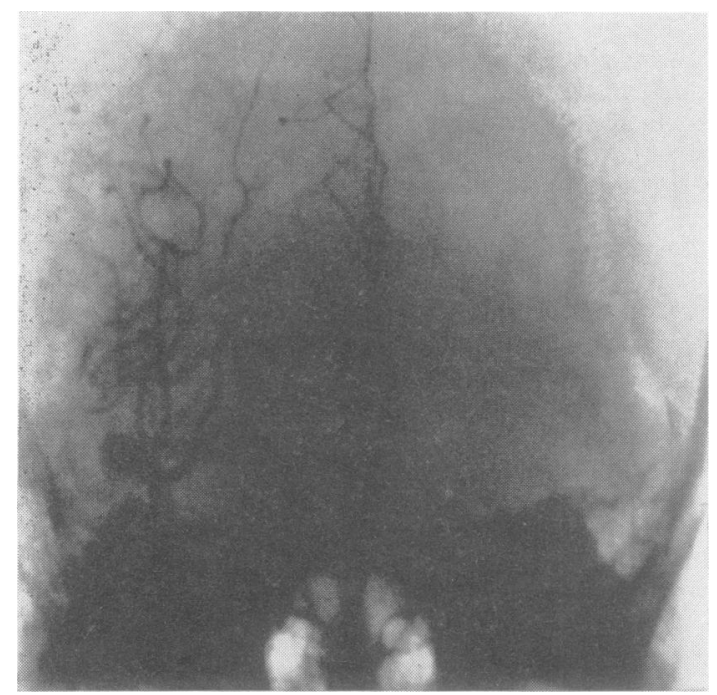

FIG. 3. Anterio-posterior view. The aneurysm is placed laterally with displacement of the middle cerebral artery inwards and the middle meningeal artery entering the aneurysm.

the dura. The artery on either side was clipped and the aneurysm was removed leaving the dura intact (Fig. 5).

The post-operative course was uneventful. The ptosis and behaviour disturbance rapidly improved, and the patient was discharged free of symptoms 14 days after the operation.

PATHOLOGICAL REPORT The specimen was a spheroidal mass with one flat surface, measuring $2.7 \times 1.4 \times 1.5 \mathrm{~cm}$.

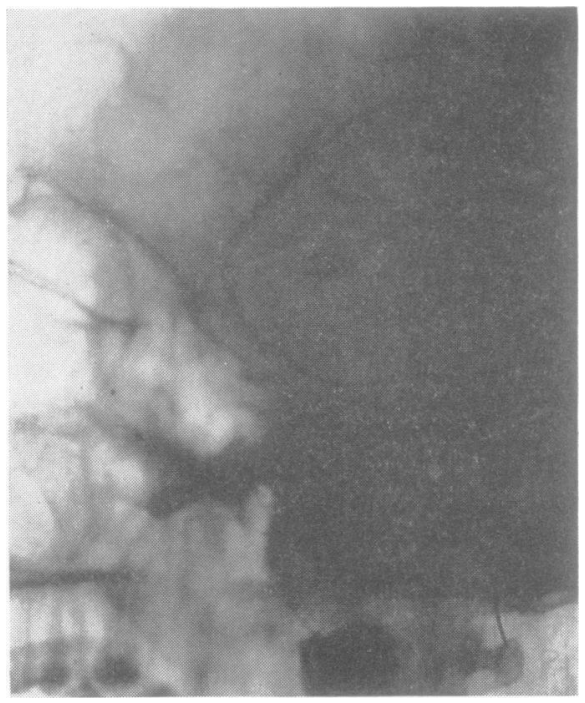

FIG. 4. Phlebogram, in which the aneurysm is still seen but the arteries are no longer visible.

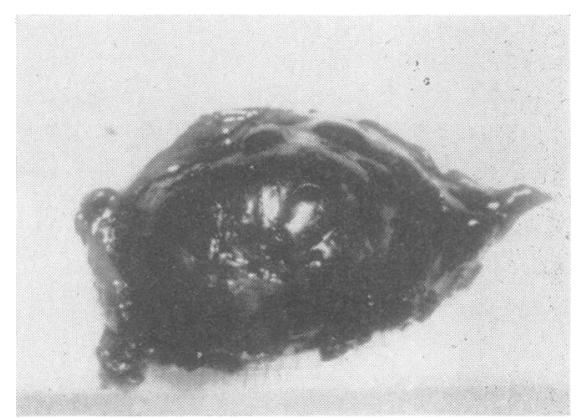

FIG. 5. Medial surface of the aneurysm.

On opening the specimen it was found to be filled with old blood clot. The wall was about $1 \mathrm{~mm}$. in thickness. Microscopically the wall had the characteristics of an artery with separation of elastic fibres and partial disappearance of muscular elements. In one place the wall had disappeared and was replaced by a thin and delicate tissue. Blood clot close to the wall was organized.

The diagnosis was rupture of an aneurysm (Fig. 6).

\section{DISCUSSION}

In 11 cases of aneurysm of the middle meningeal artery there were seven males and four females. Their ages varied from 7 to 73 years. The clinical history followed a pattern very similar to the case reported above, an initial head injury with coma lasting from a few minutes to seven days. Following a period of improvement from six to $\mathbf{4 0}$ days, symptoms of raised intracranial pressure and/or focal signs 


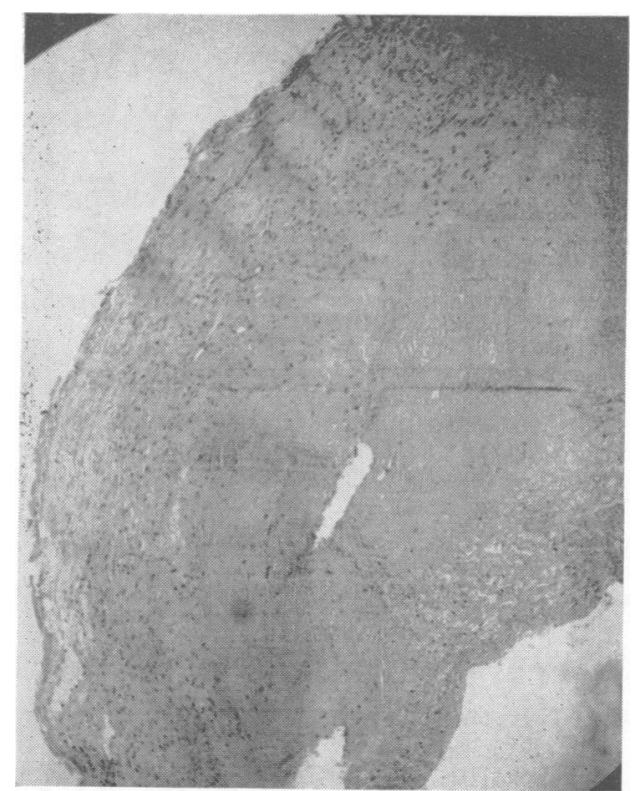

FIG. 6. Aneurysmal wall with organized blood clot.

appeared or persisted, necessitating further investigation.

In one case (Markwalder and Huber, 1961) an acute subdural haematoma was evacuated: as the patient was still in coma after seven days, serial angiography was performed and the aneurysm was discovered. In another (Pouyanne et al., 1959) the aneurysm ruptured into the brain substance one month after the injury, causing hemiplegia and coma. In both these cases the aneurysms were attached to the inner surface of the dura.

In four cases there were personality changes and mental confusion. Temporal lobe epilepsy, unilateral pyramidal signs, and third nerve paralysis each occured in one case.

In another four cases the appearance of papilloedema stimulated further investigation. In one case (Berk, 1961) pain and swelling in the temporal region were the main complaints. In this instance there was no trauma but associated Paget's disease of the skull. Straight radiographs of the skull in all but three cases had shown a linear fracture over the aneurysm. In all cases final diagnosis was made by serial common carotid angiography. In eight cases the aneurysms were extradural and in three cases subdural. All the latter had bled into the brain substance. It seems that whatever the nature of the aneurysm, true or false, the same syndrome is produced, but when the aneurysm is subdural then there is grave danger of rupture into the brain substance.
None of the reported cases of middle meningeal artery aneurysm could have been diagnosed without common carotid serial angiography. The importance of angiography in the management of head injuries has been emphasized by Lofstrom, Webster, and Gurdjian (1955), by Hancock (1961), and by other authors. Unfortunately even now the majority of cases of suspected extradural haematoma are operated on without the benefit of angiography.

Angiographic appearances are typical. In the early arteriogram the aneurysm and the external carotid system are not filled. In the later arteriogram and phlebogram they are well visualized. In the lateral views it appears as a round opaque mass adjacent to the origin of Sylvian vessels but in the anteroposterior view it can be seen well away from the midline. The meningeal artery can often be seen entering and leaving the aneurysm. Distal to the aneurysm the tramway appearance (Figs. 2 and 3 ) so often described in acute middle meningeal haemorrhage is occasionally seen (Wortzman, 1963). Displacement of the middle cerebral artery in both antero-posterior and lateral views could indicate the presence of extradural clot in the middle fossa (Figs. 1 and 3).

One can only guess at the number of cases that have been missed in the past. It is possible that at least some of the cases reported under the diagnosis of chronic extradural haematoma were examples of this condition.

In the case of false aneurysms, the initial trauma must have caused a small tear in the arterial wall, giving rise to a certain amount of extradural clot. Spontaneous arrest of bleeding had allowed a fibrous wall to form around the clot in the immediate vicinity of the artery. To postulate that the bleeding had occurred between the two layers of the dura would not explain the presence of large amounts of extradural clot or formation of the subdural aneurysms. Extradural clot which has been present for variable times up to seven weeks after injury is dark green, adherent, and in a state of organization. It is covered by a thin fibrous capsule.

Markwalder and Huber (1961) suggest that the aneurysm attached to the inner surface of the dura is associated with small vessels bridging the meningeal and cerebral vascular systems.

All aneurysms of the middle meningeal artery are potentially dangerous as they may rupture after a slight head injury, and this danger is more evident in the subdural type. In the case of the true aneurysm reported above it seems that the trauma to the skull during the fight ruptured a pre-existing aneurysm.

Subsequent loss of consciousness one hour after the injury was due to the extradural haematoma. The haemorrhage must have ceased spontaneously soon after, as often happens in aneurysm of the 
cerebral vessels. Persistence of the third nerve paralysis and personality changes were due to the presence of extradural clot in the middle fossa and the aneurysm as such was not responsible for any of the symptoms. If this patient had been operated on in the first four days after the injury when he was still in coma without serial angiography, a typical extradural haematoma would have been evacuated and the aneurysm would not have been noticed.

The extreme rarity of the diagnosed cases of aneurysm of the middle meningeal artery compared with those of cerebral arteries is surprising, specially if we consider the embryological association of the two systems and similarity of structure of the middle meningeal artery in its intracranial course with those of cerebral vessels as regards the defects in the media (Hassler, 1962). This may be explained by the protection offered to the aneurysm by the dura internally and the skull externally. Alarming symptoms produced by bleeding of unprotected cerebral aneurysms into the subarachnoid space and the brain substance make their diagnosis easier and more frequent.

\section{SUMMARY}

A case of chronic extradural haematoma due to rupture of a true middle meningeal aneurysm after a slight injury is reported. The course of the illness closely followed the pattern described by others in the cases of false aneurysms of this artery.

The importance of angiography in diagnosis and management of this condition is emphasized.

My thanks are due to Professor A. Farhad and Dr. A. Fotoohi for radiological examination, and to Professor
H. Rahmatian and Dr. M. Shamsa for the histological report and photomicrographs.

\section{ADDENDUM}

Since writing this paper three more cases of post- $\overline{\widehat{c}}$ traumatic false aneurysms of the middle meningeal ${ }^{\infty}$

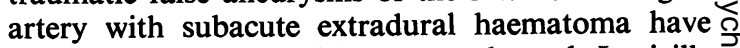
been reported by Paillas, Bonnal, and Lavieille (1964). The clinical course of these three cases closely resembled the syndrome described above.

\section{REFERENCES} Berk, M. E. (1961). Aneurysm of the middle meningeal artery. Brit. $\frac{\overline{\frac{\sigma}{\sigma}}}{\frac{\bar{\sigma}}{J}}$
J. Radiol., 34, 667-668.

Dilenge, D., and Ruthrich, R. (1962). L'anévrysme traumatique de $\overparen{\mathbb{D}}$ l'artere méningée moyenne. Neurochirugia (Stuttg.), 4, 202-206. @

Hancock, D. O. (1961). Angiography in acute head injuries. Lancet, 2, טు 745-747.

Hassler, O. (1962). Medial defects in the meningeal arteries. J. Neuro- $\overrightarrow{0}$ surg., 19, 337-340.

Hirsch, J. F., David, M., and Sachs, M. (1962). Les anévrysmes $\vec{A}$ artériels traumatiques intracraniens. Neuro-chirurgie, 8, 189- $\omega$ 201.

Kia-Noury, M. (1961). Traumatisches intrakranielles Aneurysma der Arteria meningica media nach Schädelbasis-Fraktur. (Ein $\frac{7}{\mathrm{O}}$

Fall-Bericht). Zbl. Neurochir., 21, 351-357.
Kuhn, R. A., and Kugler, H. (1964). False aneurysms of the middle $\infty$ iv meningeal artery. J. Neurosurg., 21, 92-96.

Lofstrom, J. E., Webster, J. E., and Gurdjian, E. S. (1955). Angī- graphy in the evaluation of intracranial trauma. Radiologid, $\vec{V}$ 65, 847-856.

Markwalder, H., and Huber, P. (1961). Aneurysmen der Meninge $\overrightarrow{\mathrm{g}}-\mathrm{O}$ arterien. Schweiz. med. Wschr., 91, 1344-1347.

Paillas, J. E., Bonnal, J., and Lavieille, J. (1964). Angicgraphic imags of false aneurysmal sac caused by rupture of median meningeg $\frac{D}{O}$ artery in the course of traumatic extradural haematoma (repQt of three cases). J. Neurosurg, 21, 667-671.

Pouyanne, H., Leman P., Got, M., and Gouaze, A. (1959). Anévrysme $\vec{m}$ artérial traumatique de la méningée moyenne gauche. Rupt@e un mois après l'accident. Hématome intracérébral temporạt. G Intervention. Neuro-chirurgie, 5, 311-315.

Schulze, A. (1957). Seltene Verlaufsformen epiduraler Hämatome. Zbl. Neurochir., 17, 40-47.

Wortzman, G. (1963). Roentgenologic aspects of extradural hematoma. Amer. J. Roentgenol., 90, 462-471. 